\title{
Ultrassonografia orbitária e de anexos
}

$\mathbf{O}$ exame de ultrassonografia é um dos mais realizados pelos oftalmologistas. A ecografia é o exame de eleição para analisar o segmento anterior ou posterior do globo ocular quando há opacidade de meios intraoculares. Trata-se de método de imagem com resolução maior para observação dos olhos do que a ressonância magnética nuclear ou a tomografia axial computadorizada.

Por outro lado, o exame de ultrassonografia da órbita ou anexos é pouco realizado pelos oftalmologistas. O mesmo aparelho que avalia o segmento posterior dos olhos pode ser utilizado para observar a órbita e anexos, porém vários especialistas em olhos não o fazem.

Uma das barreiras ao conhecimento sobre o exame da ultrassonografia orbitária é a escassez de cursos ou de publicações, sejam artigos ou livros, que abordem o tema em profundidade. No livro "Ultrassonography of The Eye and Orbit"(1), a técnica do exame orbitário e de anexos, bem como o diagnóstico diferencial das doenças em questão são abordados em aproximadamente 200 páginas. Portanto, quase a metade do livro (um dos mais completos sobre ultrassonografia oftalmológica) é direcionada a ecografia orbitária e de anexos. Entre as múltiplas alterações que podem ser observadas ao ultrassom estão: tumores de glândula lacrimal(1), avaliação de fase de doença de Graves ${ }^{(1)}$, análise diferencial de $\operatorname{cistos}^{(2)}$, detecção de lesões traumáticas ${ }^{(1)}$, padrões de tumores orbitários como o linfoma ${ }^{(3-4)}$, características de doenças inflamatórias como a dacriocistite ${ }^{(5)}$ etc.

A órbita é área de estudo comum a outras especialidades médicas e outros exames de imagem podem ser utilizados para avaliá-la. Qual é o melhor método de imagem para estudar a órbita? Não há um método com superioridade absoluta, por isso existem vários. A literatura médica esclarece que cada exame produz seus resultados por meios diferentes e tem suas indicações e contraindicações particulares. Os resultados dos exames de imagem não se anulam, mas podem se somar para ratificar ou não o diagnóstico clínico. Não há necessidade para um determinado caso clínico de se usar os três, mas em casos mais complicados, a utilização de todos eles poderia ser desejável. No quadro 1, observamos características diferenciais dos três exames ${ }^{(6)}$.

\section{Quadro 1}

Diferenças entre exames de imagens utilizados em oftalmologia

\begin{tabular}{|c|c|c|c|}
\hline & Ultrassonografia & $\begin{array}{l}\text { Tomografia Axial } \\
\text { Computadorizada }\end{array}$ & $\begin{array}{l}\text { Ressonância } \\
\text { Magnética Nuclear }\end{array}$ \\
\hline Energia utilizada & Acústica & Raios-x & Campo magnético \\
\hline Tempo de exame & Relativamente rápido & Rápido & Longo \\
\hline Examinador & $\begin{array}{l}\text { Em geral é realizado pelo } \\
\text { oftalmologista e a precisão } \\
\text { do exame depende } \\
\text { do examinador }\end{array}$ & $\begin{array}{l}\text { Em geral é realizado pelo } \\
\text { radiologista e a precisão } \\
\text { do exame depende } \\
\text { do examinador }\end{array}$ & $\begin{array}{l}\text { Em geral é realizado } \\
\text { pelo radiologista e } \\
\text { a precisão do exame } \\
\text { depende do examinador }\end{array}$ \\
\hline Contraste & Não usa & Iodado & Paramagnético \\
\hline Custo & Baixo & Moderado & Alto \\
\hline Contraindicações & $\begin{array}{l}\text { Necessidade de avaliação } \\
\text { do ápice orbitário }\end{array}$ & Alergia a iodo & $\begin{array}{l}\text { Possuir marca-passo } \\
\text { cardíaco, Implante coclear } \\
\text { ou ter claustrofobia }\end{array}$ \\
\hline
\end{tabular}


Conforme observamos no quadro acima, a realização mais frequente da ultrassonografia da órbita e anexos pode reduzir custos no sistema de saúde, valorizar mais o oftalmologista e evitar os efeitos adversos dos raios-x ou complicações associadas à exposição ao campo magnético. Portanto, penso que iniciativas para aumentar o ensino, a prática e publicações envolvendo este tipo de exame são importantes.

\section{Arlindo José Freire Portes \\ Mestre e Doutor em Oftalmologia pela UFRJ \\ Professor Titular de Oftalmologia da Universidade Estácio de Sá - RJ Editor-Chefe da Revista Brasileira de Oftalmologia}

\section{REFERÊNCIAS}

1. Byrne SF, Green RL. Ultrasound of the eye and orbit. 2nded. St Louis: Mosby; 2002.

2. Ghanem RC, Monteiro ML. Cisto hemático intraconal espontâneo de órbita. Relato de caso. ArqBras Oftalmol. 2002;65(4):479-82.

3. Couto Jr AS, Barbosa RS, Portes AL, Portes AJ, Benchimol ML. Lnfoma orbitário- relato de casos e apresentação atípica. RevBras Oftalmol. 2000; 59(10):759-63.

4. Docampo J, Santoro D, Bruno C, Morales C. Fibromatosis orbitaria solitária. Reporte de caso. RevArgent Radiol. 2010; 74(1):43-6.

5. Lorena SHT, Silva JAF. Dacriocistite aguda: relato de 2 casos. RevBras Oftalmol. 2011; 70(1):37-40.

6. Watanabe M, Morais CA, Couto Jr AB. Considerações sobre eficiência administrativa relacionada aos exames de ultra-sonografia, tomografia computadorizada e ressonância magnética nas afecções orbitárias. RevBras Oftalmol. 2007; 66(6):376-82. 